Article

\title{
The Banality of Digital Reputation: A Visual Ethnography of Young People, Reputation, and Social Media
}

\author{
Sander De Ridder \\ Department of Communication Studies, University of Antwerp, Belgium; E-Mail: deridder.sander@gmail.com
}

Submitted: 11 February 2021 | Accepted: 2 April 2021 | Published: 13 September 2021

\begin{abstract}
This article relies on a visual ethnography with young people between 13 and 20 years old. Young people were asked to make visual collages of fictional social media accounts, which are used in this article to analyse the signification of "good" and "bad" reputation in digital youth culture. It explores how reputation is performed visually and aesthetically in digital youth culture. The aim is to contribute to the critical study of digital reputation, it formulates an ethical critique on how the signification of digital reputation has formed alongside values and beliefs that support the growth of platform capitalism, rather than assigning a reputational value and rank responsibly. I conclude how the signification of digital reputation is not only conformist and essentialist but also meaningless. The banality of reputation argues that, in the context of popular social media, there is no real or substantial information made available to distinguish between a "good" or a "bad" reputation, except for stylized banality, a stylistic focus on lifestyle and commodities. The point is that reputation should not be banal and meaningless. Many important political and institutional decisions in a democracy rely on the evaluation of reputation and critical assessment of the information upon which such evaluations are made. Although platform capitalism has made digital reputation meaningless, it is in fact an essential skill to critically orient oneself in digital societies.
\end{abstract}

\section{Keywords}

banality; digital media; digital reputation; Instagram; platform capitalism; social media; visual ethnography; youth culture

\section{Issue}

This article is part of the issue "From Sony's Walkman to RuPaul's Drag Race: A Landscape of Contemporary Popular Culture" edited by Tonny Krijnen (Erasmus University Rotterdam, The Netherlands), Frederik Dhaenens (Ghent University, Belgium) and Niall Brennan (Fairfield University, USA).

(C) 2021 by the author; licensee Cogitatio (Lisbon, Portugal). This article is licensed under a Creative Commons Attribution 4.0 International License (CC BY).

\section{Introduction}

Reputation is a high-stakes issue in the public sphere and popular culture. The so-called "cancel culture," the "withdrawal of any kind of support (viewership, social media follows, purchases of products endorsed by the person, etc.) for those who are assessed to have said or done something unacceptable or highly problematic" (Ng, 2020, p. 623), has been the downfall for a significant number of celebrities in the past few years. High-level cases of reputation loss have illustrated that, despite outstanding reputation management for decades, a sudden and shocking fall from grace could happen to any star.

Yet concerns regarding the potential that one may experience a downfall caused by a rapid and unpre- dictable drop in reputation status resonate beyond the world of stars. Reputation capital, one's accumulated status and rank, is an asset that especially in the context of digital media is a concern for young people and their parents too, with Pew Research Center surveys showing that teens are active reputation managers. A majority of parents are also "very concerned" about digital reputation (Madden et al., 2013). Safeguarding children and young people's future reputation capital when living a digital life is not easy. "Bad" decisions, for example, a nude picture circulating without consent, might forever circulate- "trending" algorithms are unforgiving technologies.

Digital reputation and how it is experienced (through shame, guilt, popularity, and influence) causes harm in 
digital life. While reputation might encourage people to improve themselves, "good" digital reputation is, as I will argue, also conformist and essentialist. Indeed, digital reputation is a kind of violence; it may produce or reinforce pre-existing social inequalities and hamper people's ability to live alongside those in society who are different. While reputation is symbolic, constructed, and performed in nature, it has enormous psychological and social-material value; "to exist means to be assigned a value in a ranking, in a system that makes comparisons possible. To be is to be comparable" (Origgi, 2019, p. 158, original emphasis). In this article, I will explore value and rank in the context of social media and young people's digital cultures by asking: What does digital reputation signify in digital youth cultures?

Digital reputation has mainly been the domain of management studies, exploring how brands, organizations, and individuals can monitor reputation as well as how online techniques and methods can be used to make something more attractive (Schultz et al., 2000). Further, media literacy pundits have argued that online reputation management should be an essential skill, emphasizing the importance of privacy settings and the risks of oversharing things online. More critical explorations of digital reputation remain understudied, however. Recently, Gandini (2016) argued that the commercial measurements of someone's individual digital reputation has become a determinant factor for career success (e.g., measurements of "social influence" based on numbers of followers on social media). Further, Rosamond (2019) has argued that the 2016 presidential Trump campaign, which mobilized trolls to capitalize on the volatility and loss of reputation, introduced "reputation warfare" as a dominant digital reputation paradigm. Rosamond argues that reputation volatility is the new norm, instead of secured reputation measurement and capital.

My aim is to contribute to the critical study of digital reputation by focusing on how conformist and essentialist interpretations of digital reputation have been formed alongside values and beliefs supporting the growth of platform capitalism (Srnicek, 2016). My objective is to ethically critique the moral economy of digital reputation in the context of social media and digital youth cultures (Hesmondhalgh, 2017; Sayer, 2007), and to assess how significations of "good" and "bad" reputations reference "proper activities" that support the platforms' business. To do so, I will use a visual ethnography (Pink, 2013) to analyse how digital reputation is symbolically made sense of by young people between 15 and 20 years old, focusing on aesthetics and visual self-representations of "good" or "bad" digital reputations.

I consider the critical study of reputation in digital youth cultures important because while "digital reputation management" is taken for granted as a digital media literacy strategy, it may reinforce social exclusion. It benefits platform capitalism more than it benefits young people and society. I will conclude by making an argument that digital reputation has become banal; "good" repu- tation signifies meaningless self-representations, tropes and clichés, commodities and instagrammable lifestyles. "Bad" reputations signify the spectacle of reputation volatility, the loss of digital reputation and the practice of shaming as entertainment. The banality of reputation is, however, not a good thing for democracy or society (Origgi, 2019). While reputation is constructed and performed, the assessment of rank and value cannot be left to radical relativism or instagrammable tropes. Assessing reputation in a contextualized, fair, ethical, critical, and compassionate way is an important, certainly not banal, skill.

\section{The Formation of Digital Reputation}

Reputation is often seen as a "mark of modernity" but Origgi (2019) argues this is a mistake. Rather, reputation is central to human psychology: "Anxiety about how we see ourselves seen exists in all cultures and manifests itself at a very early stage of child development" (Origgi, 2019 , p. 24). Despite it not being modern, reputation has, since the early 2000s, become a central feature of people's digital lives and taken on particular significance in Western societies and culture-it is this particular significance that I will explore in this first part.

From a socio-cultural perspective, the formation of digital reputation might be seen as a language containing no essence but formed in "shifting relations of difference" and as such establishing itself "with other concepts and ideas in a signifying field" (Hall, 1997); while the essence of the distinctions between "good" and "bad" reputations might be mysterious, their meanings are fixed in particular socio-cultural formations at a particular time. For example, in digital youth cultures, reputation establishes itself with culturally specific normative believes about gender when girls are shamed disproportionally more than boys for "harming" their online reputation by taking too sexy selfies (Korkmazer et al., 2020). The socio-cultural work of digital reputation organizes people into different social groups and acts as a means of "social human classification" (Hall, 1997).

I want to argue, however, that the significance of digital reputation in digital lives has been formed alongside specific technocultural transformations such as the transition to a user-generated web in the early 2000s. Built around online participation, self-representation, and the data-driven business models of platforms such as Facebook, this technocultural formation meant the end of the pre-commercial internet (Lovink, 2012). Popularity on the internet became seen as the foundation for a career, a gateway to digital entrepreneurship for the aspiring young (McGuigan, 2014). Methods and techniques to systematically manage digital reputations became something that could be employed not only by corporate brands (Schultz et al., 2000) but also by ordinary people. The shifting boundaries between public and private life brought a new kind of "information war" (Thompson, 2011), giving power and 
"creditworthiness" (Rosamond, 2019) to those with good reputations. Around 2006, high-level stories of cyberbullying and revenge porn started to circulate and made way for Reputation.com, the first online reputation management agency providing services to those who need help with public shaming on the internet (Ronson, 2015).

The power of digital reputation, but also how meanings of digital reputation shift and are re-appropriated, have made digital life vulnerable and exhausting. A moment of clouded judgement may lead to a loss of reputation. A poorly formulated tweet, a drunken picture, or sexting gone wild reduces someone to a single "bad" decision (Phillips \& Milner, 2017). The searchability and durability of online content, but also how gossiping, shaming, and rumours are characteristic of digital sociality are ongoing threats to digital reputations. In the technocultural formations of contemporary digital life, reputation is seen as capital turning "reputation" into a financialized asset. Reputation capital, as defined by Rosamond (2019), is a form of what Bourdieu (1994) refers to as "symbolic capital": "The aggregated value of signs indicating the perceived esteem, honour, respect, likeability, importance and/or trustworthiness attributed to a given person or entity, understood as the person or entity's intangible asset" (Rosamond, 2019, p. 4). Digital tools for monitoring financialized reputation are assumed to "rationally" and "objectively" measure reputation capital across social media platforms. Yet, while reputation capital is assumed to be steadily built over time, it is the volatility and the potential loss of reputation that characterizes reputation's financialization.

For ordinary youths, the financialization and volatility of digital reputation produce expectations and requirements to maintain "good" reputations so as to not jeopardize their social value and (future) reputation capital. In everyday life, despite being symbolic in nature, digital reputation is interpreted as the essence of the digital self that, once damaged, is difficult to fix. An example in digital youth cultures is the stigmatization of "those who send sexts": Young people are harshly judged and excluded from their peer groups when sexting because they have failed to maintain "good" reputations (De Ridder, 2019), they have failed to protect their future reputation capital. Digital reputation is an individual responsibility that needs to be defended relentlessly, for a loss of digital reputation may be weaponized against you (Rosamond, 2019) as some may find pleasure in seeing your digital reputation destroyed. Reputation is an important part of the affective experience of daily digital life (e.g., anxiety, exhaustion, shame, and humiliation) as its undoing means a rupture of one's digital self (Origgi, 2019, p. 21).

\section{Platform Capitalism, Social Media, and the Moral Economy of Reputation}

So far, I have argued that the financialization of digital reputation refers to reputation as a calculable asset of people's social value and to the idea that a "good" digital reputation is necessary to build a career in today's knowledge economy: When maintaining "good" digital reputations there is the expectation of an economic return (Gandini, 2016, p. 27). Moreover, I have argued that concerns about digital reputation are central to the affective experience of digital life. In this part, I will further explore how digital reputation is a "product" of the commercial internet and platform capitalism, and how the significance of digital reputation is formed alongside the norms, values, and beliefs that support the growth of platform capitalism.

I refer to the moral economy of digital reputation to explore the values and beliefs of what constitutes the social human classifications of a "good" reputation in the context of social media (Sayer, 2007). Platform capitalism, like any other economy, is "suffused with values and beliefs about what constitutes proper activity, regarding rights and responsibilities of individuals and institutions and qualities of goods, service and environment" (Hesmondhalgh, 2017, p. 206). A moral economic approach to digital reputation asks critical questions about platform capitalism's validity to make distinctions between "good" and "bad" reputations. A moral economy approach to digital reputation is an ethical critique of platform capitalism, yet it also invests in politics and power; the distinctions between "good" and "bad" reputation might (re)produce particular kinds of violence that need to be addressed, it may reinforce already existing inequalities and eventually hamper people's ability to live alongside those who are different.

The platform, as argued by Srnicek (2016), is a firm built around the handling of data for profit. The platform business affects every sector of the economy, but my focus here is primarily on social media and the technology that they use for facilitating online participation and self-representation. The economic operations of social media platforms are more than a shift in the business models of the internet, they are "an ideal that can legitimate contemporary capitalism more broadly" (Srnicek, 2016, p. 12). Platform capitalism is a hegemonic model that can be applied to different businesses and sectors (e.g., Srnicek provides the example of how cities are expected to become "smart") and social media applied that model to facilitating and organizing sociality, communication, and connection by extracting data from its users. I argue that there are two key values and beliefs to how platform capitalism's hegemonic model assesses reputation in the context of social media. The first is an expectation that one's digital self and identity needs to be managed, the second is that one is able to master popularity and as such gain influence.

First, the efficient management of digital reputation relies on authentic self-promotion, which means promoting the self in a "natural" way, staying true to so-called "innate qualities" of the self (Grazian, 2018). Ideally, a digital identity with a "good" reputation avoids anonymity, is transparent, coherent, and stable across 
platforms. This is something that platform capitalism has a "vested interest in pushing as the need for a uniform online identity attained maximum transparency, not only because they want to know who their users are, but also because advertisers want users 'truthful' data" (van Dijck, 2013, p. 200). Such a belief of what constitutes a "proper" online identity was initially pushed by Facebook (Kirkpatrick, 2010) but broadly pushed a "hegemony of a single identity" in digital culture (van Zoonen, 2013). Today, popular mobile applications such as Snapchat and Instagram allow more playful engagements with the self and identity-Instagram supports multiple accounts for users to engage with different groups of followers (Leaver et al., 2020)-yet the demand for coherent identity management is unlikely to change, precisely because it is at the core of platform capitalism's hegemonic model of sociality.

Second, digital reputation is a matter of mastering popularity and influence, primarily supported by technology that allows social media users to manipulate algorithms in order to make particular people, issues or topics trend by "liking" and "sharing." Social media algorithms are in fact reputational technologies: They continuously measure social value and reputation capital ambiguously. Algorithms are opaque, which contributes to the volatility of digital reputations. Algorithms' lack of transparency also makes them exciting (Gillespie, 2018). Reputational technologies play an important role in how reputation's volatility is capitalized upon: "Tactical interventions" (e.g., large numbers of people "liking" or "sharing" at the same time) may quickly make or break a reputation, making digital reputation a powerful (political) weapon in culture and society (Rosamond, 2019). The logic of popularity is a battleground for the digital reputation to be made and unmade. The attractiveness of the unfolding spectacle of a broken reputation supports platform capitalism, as it generates more traffic and time spent on social media.

\section{A Visual Ethnography of Reputation in Digital Youth Cultures}

This article relies on a visual ethnography to explore the signification of digital reputation. Digital reputation is primarily negotiated visually in contemporary youth culture: Popular social media platforms and apps such as Snapchat, TikTok, and Instagram have produced an intense influencer culture that focuses on visuality. Instagram in particular has heralded "a new class of content creators who strive for authenticity on a platform best known for selfies and self-representation" (Leaver et al., 2020, p. 26). In contemporary digital youth cultures, reputation is often aesthetically negotiated by means of beautiful images: Such images have gained significant social and economic influence in contemporary culture (Manovich, 2020). Because digital reputation's signification is primarily negotiated visually, a visual ethnography is well suited to providing insight into digital reputation in youth culture. As Pink (2013, p. 16) notes, the visual is often interwoven with "our personal identities, narratives, lifestyles, cultures, and societies." Visual ethnography is a means to produce situated knowledge through images about (digital) everyday life.

To research the signification of digital reputation in digital youth culture, visual research materials that young people produced during ethnographic research were collected. The analysis of these visual research materials allowed me to explore how digital reputation is constructed and performed. These analyzed visual research materials are not realist representations of digital reputation but symbolical explorations of reputational signifiers such as "esteem, honour, respect, likeability, importance and/or trustworthiness" (Rosamond, 2019 , p. 4). During the ethnographic research activities, participants were divided into groups and asked to visually design fictional social media accounts with a good or bad reputation by drawing and/or using magazines to produce visual representations of imagined social media profiles. During these research activities, conversations with the research participants about the representations that they produced were recorded and transcribed, these conversations also formed part of the research data. I chose "analogue" visual research materials instead of digitally available visual material (e.g., pictures circulating on Instagram) to consider the "digital intangible" (Pink et al., 2015, p. 72). Such a non-digitalcentric approach is a powerful method to explore how the digital has become part of the every day and the social worlds that people inhabit. Such an approach does not focus on the digital, but on the complex relationship between people's digital and social worlds.

I analyzed the visual research materials by categorizing them as presenting a "good" or "bad" reputation, allowing me to explore the significance of this distinction. I explored (1) how reputation was constructed and performed visually and aesthetically through symbolic motives. Then, drawing on a moral economy approach I explored (2) how distinctions between "good" and "bad" were validated by hegemonic ideas that relate to platform capitalism. I took a reflexive approach to analyzing these materials, which means it was a collaborative effort between my own interpretations of the visual research material and the interpretations of the young people involved in the study.

My approach to the visual data is not rooted in a semiotic approach to those images as "texts," I did not read those images in isolation. Rather, a visual ethnographic approach (Pink, 2013) recognizes how these visual images are interwoven and connected to people's identities, as well as how they are part of the wider environments in which people live, such as people's social life-worlds and the technologies that are part of everyday life. As I have previously argued, the signification of digital reputation may produce classificatory systems through language; however, it is only when these classificatory systems become a factor in everyday 
life through their interwovenness with practices, affective experiences, and technologies that digital reputation may become powerful by regulating people's conduct and experiences which may therefore potentially produce or reinforce inequalities.

\subsection{Introducing the Participants}

The visual ethnography presented in this article is part of a four-year research project (2017-2021). The project explores how digital reputation relates to everyday power struggles of young people based on gendered, sexual, ethnic, and religious identity intersections. The goal of this project is to find alternative strategies to improve young people's online well-being which go beyond a highly individualized focus on "online reputation management" and take into account the dynamics of exclusion and subordination, related to multiple identity experiences. This study supports this need as this research has been conducted with a diverse group of young people who were actively engaged in the research process (Sue et al., 2009).

The research presented in this article is empirically driven, yet it is anti-positivist. Such an approach demands that the presented discussions are "radically contextualized" (Ang, 1995), which means considering spatial and temporal settings, as well as bearing in mind the particular social categories and formations of the participants. The participants, all of whom live in an urban region of Dutch-speaking Belgium were recruited from two different secondary schools and one youth organisation. The first school offers a general education (preparing students for higher education), having a mostly white, middle-class student population. The second school offers a vocational education, having an ethnically diverse, and mostly lower-middle-class student population. Finally, the youth organisation focuses on empowering urban youth who are experiencing difficulties, helping them to navigate life, offering guidance with finding a job and/or leisure activities, with mostly lowermiddle-class youths being involved in this organisation. In total, 29 ( 23 female and 6 male) youths between 15 and 20 years old participated in the production of the visual research materials presented.

\section{Symbolizing "Good" Digital Reputation}

The visual research materials are, as shown in Figure 1, creative collages that made use of sketches to get across what they wanted to communicate about digital reputation. Other than sketches, participants used a broad selection of magazines that were provided by the researchers, allowing participants to look for fitting visual material. In total, 10 collages that signify "good" digital reputations were included in the analysis, referring to typically banal tropes and clichés. First, participants used the "tropes and clichés" of what is Instagrammable (Leaver et al., 2020). Instagrammability signifies an "ideal" genre of visual self-representation that has become the norm across platforms and not just on Instagram. Second, visually communicating virtues such as having a positive attitude, volunteering, and supporting left-liberal activism were found to signify a "good" digital reputation. Representing such virtues through circulating beautiful images and attractive lifestyles supports digital reputation's banality. Often, there is no interest in structural solidarity (Moran, 2014, p. 153), yet there is the expectation of an economic return when symbolizing solidarity and optimism on popular social media.

\subsection{The Instagrammability of Reputation Capital}

The visual aesthetics of a good reputation are built around showing off one's importance and likeability. The collages show a visual economy of repetition around the themes of being athletic and fit, eating healthy instagrammable foods, being popular among friends, travelling, showing luxury consumables such as watches and sunglasses, having a relationship (\#couplegoals), and being artsy and bohemian. A use of aesthetically pleasing compositions, poses, filters, or having a consistent style in your profile (such as all black and white pictures) are markers of one's digital reputation. All of the collages showed how the metrification of one's popularity is important, having a significant following base indicates influence-more than 1,000 followers seemed to be the norm, but some collages made references to 1,3 million followers. Also, accounts that do not follow as many profiles as they have followers themselves are granted reputation capital.

The visual collage of the fictional Instagram account of Jean-Paul, an account having 1,3 million followers, is an example of how the commodification of reputation (Kurzman et al., 2007) is at the core of being an internet celebrity. Jean-Paul, as argued by the participants, made a lucrative career from vlogging on YouTube, which he shows off on Instagram:

We have a handsome guy, he has pictures of healthy eating, from luxury clothes such as Balenciaga and other expensive brands. You can see he has lots of money, he shows his nice cars, shoes, and travels.... He is a Dutch YouTuber, and he is also gay. (Describing the collage of Jean Paul)

Yet, on the other hand, the unpretentious authenticity of the fictional Instagram account of Sarah Snow with 2,035 followers, shows that one's reputational capital is not related to being an internet celebrity per se. Presenting as middle class, likeable, and a socially attractive personality is also an example of a "good" digital reputation:

We have a very normal girl. She has pictures from her most beautiful moments. The pictures on her profile show she has a new dog, bought a new outfit, that 


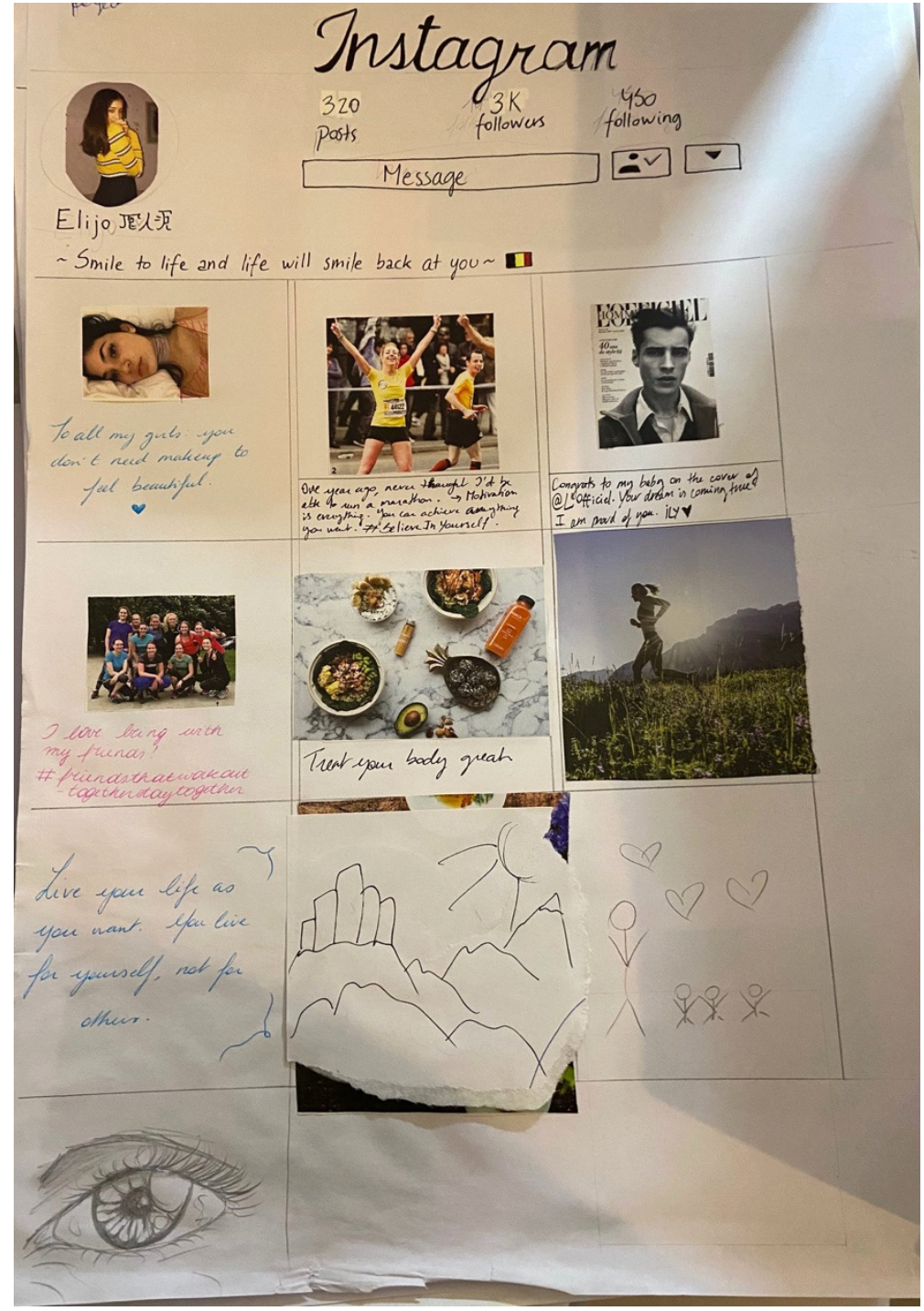

Figure 1. Fictional Instagram of Elijo symbolizing "good" reputation.

she went to a nice bar, and that she celebrates having been together with her boyfriend for over a year. (Describing the collage of Sarah Snow)

Good reputations were symbolized in different ways, ranging from being the handsome internet celebrity or the "ordinary" Instagram girl next door. Yet both the collages of Jean Paul and Sarah Snow agree that one's visual identity should be well-defined and personal, displayed through a distinctive choice of commodities and clothes, lifestyle, and image (Moran, 2014, p. 153).

Instagrammable reputation capital drives consumer capitalism, and thus platform capitalism (Srnicek, 2016). The focus on instagrammable reputation capital is yet another way to extend capitalist production and the creation of new markets (Moran, 2014). These new markets, which produce new consumables that are used to signify one's reputation capital, are lucrative business for social media platforms. They profit from time and traffic spent on the platform when people do the work to shape one's "personal identity" and they profit again from tar- geted advertising, selling consumables that people need to shape a well-defined identity.

\subsection{The Communication of Virtues as Reputation Capital}

The fictional Instagram account Ilijo signifies good reputation by posting optimistic inspirational quotes such as "smile at life and life will smile back at you," the account of Poyraz Aktas shows pictures symbolizing helping children in poverty, and finally the fictional Instagram account Troye Sivan shows pictures symbolizing LGBT activism and joining protest marches. The attention to visualizing virtues such as optimism, fairness, inclusivity, and diversity on social media was seen as crucial to building reputation capital, but the participants recognized the irony of performing such a social consciencethere is a performative aspect to signalling such virtues on visual social media. For example, when describing the fictional Instagram account of Sofie Demeers, virtues such as "doing charity work" and "getting to know different cultures" were recognized as clichés of visual 
self-representation: "She has 1,099 followers. She has pictures from doing charity work when she went on holiday to learn a new language, to get to know different cultures, and all that "blablaba'" (describing the collage of Sofie Demeers).

Rather pessimistically, Cremin (2012) refers to performing such a left-liberal social conscience as "guilt fetishism"; it shows compassion but ignores the structural foundations of inequalities, often there is a resistance towards a more fundamental engagement with inequalities. While this is a pessimistic take, there is something to say about this in the context of digital reputation. As I have previously argued, the moral economy of reputation is built around the expectations of economic return when maintaining a "good" digital reputation; creating a self-brand based on positivity and compassion works well for influencers as it opposes shame and scandal (Leaver et al., 2020, p. 220). Further, visualizing virtues allows you to distinguish your personal identity. This is something that participants recognized that might help you to "find a job":

Interviewer: Why does this profile focus on doing charity work and being involved in activism?

Participants: It's just....People like it. It's good to volunteer! It makes it easy to find a job in the future. (Describing the collage of Poyraz Aktas)

Identity management focuses on distinguishing yourself as respectable and likeable, for which the com- munication of positive virtues is a powerful strategy. The hegemonic model of platform capitalism has helped to introduce this "wish to do good." Digital entrepreneurs typically celebrate left-liberal values and a "neo-hippy manner" way of doing business (McGuigan, 2014). Building reputation capital means showing yourself as being part of such a "wish to do good." However, such a moral economic principle deserves ethical criticism, as it might also work against the "emancipatory, solidaristic potential of the social notion of identity" (Moran, 2014, p. 153).

\section{Symbolizing "Bad" Digital Reputation}

In total, four collages that signify "bad" digital reputation were included in the analysis. Three of these accounts were "anonymous," signifying not identifying with your real name as a marker of a bad reputation. There are two ways in which "bad" digital reputations were symbolized. First, there was an agreement that sexual content harms reputation capital. Second, it was seen as bad to engage in online trolling and shaming. These are practices to which I will refer to as "reputation warfare."

\subsection{Sexual Content Harms Reputation Capital}

Figure 2 is the fictional Instagram account of Chanel, showing a collage of female nudity that symbolizes sexual content by showing practices such as sexting (sharing [semi-]nude pictures online), glorifying being a "stripper," teen pregnancy, having a sugar daddy, and

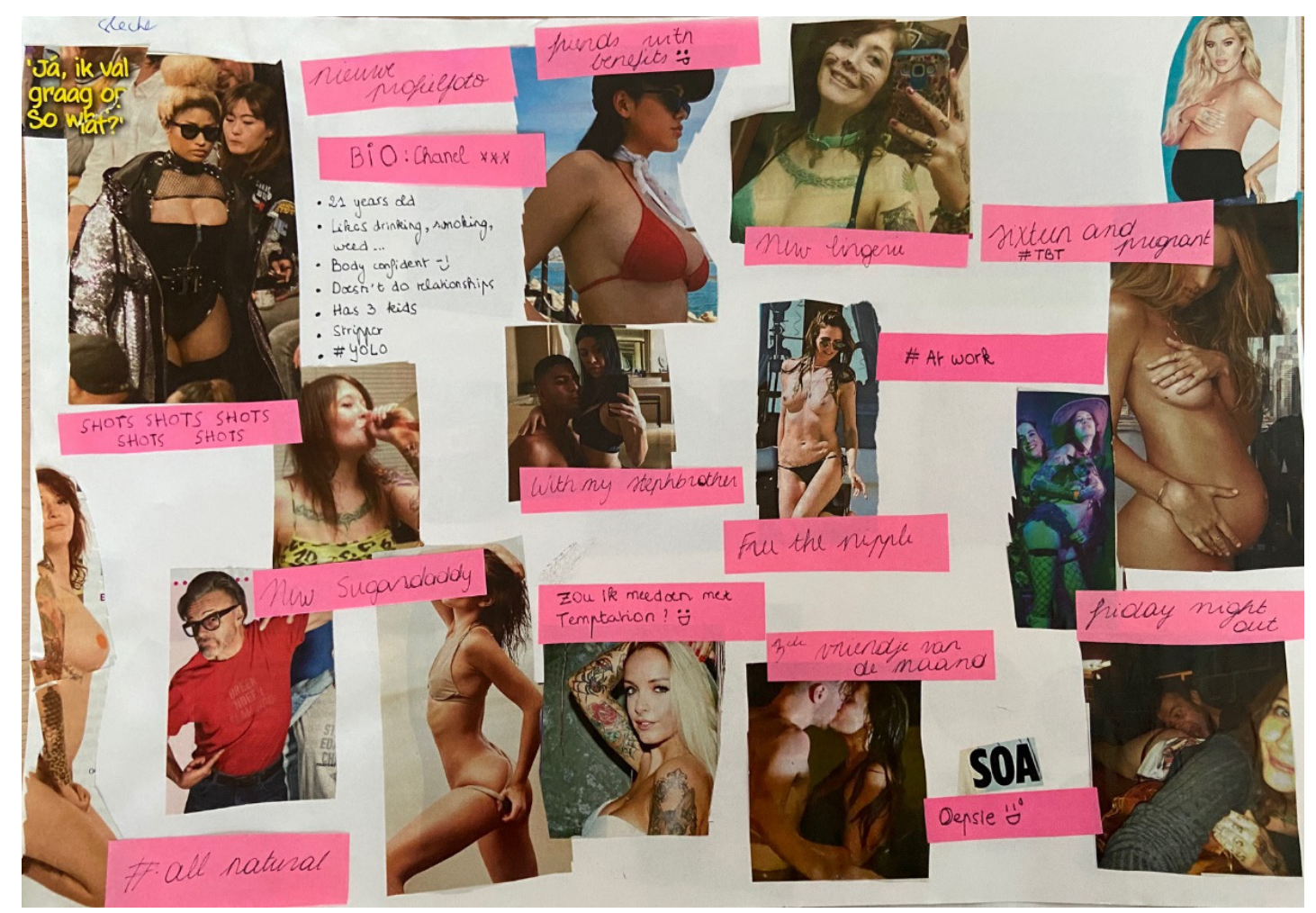

Figure 2. Fictional Instagram of Chanel symbolizing "bad" reputation. 
participating in reality-TV shows such as Temptation Island. The meanings assigned to those self-representations were paradoxical. On the one hand, participants described those visual self-representations of nude female bodies as "beautiful." On the other hand, they agreed that nudity can cause conflict and harm an individual's future reputation capital, certainly among females and/or those who are "ordinary" as opposed to (internet) celebrities. Digital reputation is gendered (Salter, 2016) and reputation capital is lost, gained, or maintained in different ways for different social groups: "A guy is allowed to show more nudity than a woman. When a guy poses in his swimsuit no one cares, but when a woman is posing in a swimsuit, most people are immediately offended" (describing the collage of Chanel).

Maintaining a "good" reputation avoids not having pictures circulating that can be weaponized against you and that may destroy your digital reputation. Notoriously, sexual content has posed content moderation challenges for popular social media platforms (Gillespie, 2018). In many ways, digital reputation is a regulatory regime for sexual self-expression; high-level stories of public humiliation and revenge porn (Ronson, 2015) teach people how posting sexual content is a bad idea. Platforms are institutional agents that make choices of what nudity is "acceptable" and they have an interest in pushing the idea that online nudity is wrong. Popular platforms allow users to share only limited experiences of bodily pleasure in order to remain attractive to a mainstream pool of users and advertisers (Gillespie, 2018).

\subsection{Reputation Warfare and the Volatility of Reputation Capital}

The distinction between "good" and "bad" reputation was not always clear. Accounts that symbolized "good" reputation were also discussed as sometimes having "bad" features. Particularly those accounts of internet celebrities were found to be both "inspiring and depressing." When influencers show off too much they eventually risk losing their authenticity and "naturalness":

I do not trust such types. From where do they have the money to show off? Probably because they are getting the money from posting that stuff I guess, but I think it is misleading. Most of the time you would think "oh so perfect," but in the end... their life is just as boring as yours. (Discussing the collage of Jean Paul)

Discussions about "bad" reputation revealed the volatility of digital reputation, or how popular social media are a battleground for the making and unmaking of digital reputation. Reputation warfare, what Rosamond (2019, p. 14) defines as "capitalizing on reputation volatility," provides excitement and the pleasure of judging other's reputations and seeing them fall. An unidentified fictional Instagram account (its anonymity reveals its status as not being "truthful") engaged in posting "not pictures of himself but pictures that shame others." While this is, as the participants stated "bad" it is nevertheless "fun to follow."

Finally, the fictional Facebook account of Gerard Zuurpruim symbolizes a middle-aged white man who is an internet troll and "sees nothing positive in life and who is friends with Donald Trump on Facebook." Moreover, "he ridicules everyone and everything." Gerard Zuurpruim symbolizes what Rosamond (2019) sees as a "paradigmatic shift" in how reputation is made sense of in culture and society since the 2016 Trump presidential campaign, in which destroying reputation became a "pleasurable spectacle" from which platform capitalism has benefitted. The aim of Gerard Zuurpruim is to strategically "[produce] reputational volatility" (Rosamond, 2019, p. 3). It shows that, given the high stakes of defending one's reputation capital, the signification of digital reputation as "war" has become a meaningful aspect of ordinary digital life, making digital reputation particularly vulnerable and exhausting, not only in the arena of politics but also in digital youth culture.

\section{Conclusions: The Banality of Reputation}

So why then, despite the signification of digital reputation, do I claim that digital reputation is "banal"?

I refer to digital reputation as "banal" (Shinkle, 2004) to argue there is a particular attitude towards "reputation"-how people assign value and rank-that is formed alongside values and beliefs that are in the best interests of platform capitalism. I have observed how the attitude towards digital reputation signifies the use of a particular aesthetic that focuses on trivial pleasures, commodities, marketable lifestyles, and performative left-liberal virtues. Moreover, that "banal" attitude assesses information that distinguishes between "good" and "bad" reputation not based on someone's qualities, but rather on their belonging to a social group; reputational distinctions are driven by classificatory systems based on essentialist, gendered, middle-class values, beliefs, and activities.

Such a moral economy of reputation based on the suppression of difference and diversity deserves to be fiercely criticized. "Good" reputations were primarily discussed as gendered by participants, maintaining and reinforcing gendered double standards. Moreover, class was also discussed as a significant marker of reputation in visual social media. Showing wealth combined with messages of doing good and giving back are markers of reputation capital and distinction in the context of visual social media. Finally, race was less explicitly visualized and discussed as a marker of digital reputation but it deserves further exploration, particularly given the significance of reputation warfare for politics following Trump.

My point is that digital reputation is "banal" because platform capitalism made it meaningless. While a "good" digital reputation has a clearly identifiable style and 
aesthetic in digital youth culture, it operates in a void that is filled with commodities, opaque algorithms, and reputational warfare. The banality of digital reputation means that the assigning of value or rank is made without any agent taking epistemic responsibility for doing so (Origgi, 2019, p. 160); no real or substantial information is made available to distinguish the "good" from the "bad" reputations in popular social media, except for stylized banality, filled with materiality and commodities.

The point is that reputation should not be "banal" and made meaningless. Many important political and institutional decisions in a democracy rely on the evaluation of reputation and critical assessment of the information upon which such evaluations are made. Yet, the assigning of value and rank should be carried out responsibly, precisely to protect social groups from exclusion and democracy from manipulation. As Origgi (2019, p. 162) states, the responsible assigning of reputation is a significant socio-cultural and technological challenge: "We still lack appropriate and effective methods for navigating among epistemic hierarchies and guarding against an obtuse and potentially authoritarian manipulation of ranking methods that affect and can sometimes unfairly solidify reputations."

In digital societies, there is agreement that children and young people should be taught the "digital skills" to uphold a "good" digital reputation across platforms to safeguard their future reputation capital. These digital skills are aimed at making young people aware of the searchability and durability of online content by, for example, focusing on the importance of privacy settings and the dangers of sharing (semi-)nudes. While this is done with the best intentions, focusing on techniques for online reputation management is missing the point. It maintains the banality of digital reputation and often relies on social-cultural dynamics of human classification to distinguish between "good" and "bad" reputations. Rather, focusing on contextualized, fair, ethical, critical, and compassionate assessments of information for making decisions about reputations are skills that will be much more beneficial to digital societies in the long term.

Finally, I would like to emphasize that my own assessment of the signification of reputation in digital youth cultures as "banal" is no judgement of young people's social media practices, but an ethical critique on platform capitalism. In digital life, there may be many reasons for which banality may in fact not be meaningless. For one, in a cultural climate where reputation volatility is capitalized upon, banality works as a shield for reputational warfare tactics such as shaming, bullying and humiliation. Stylized banality - "smile at life and life will smile back at you" - eases the affective burden that comes with maintaining one's digital reputation.

\section{Acknowledgments}

This article is part of a project that has received funding from the Research Foundations Flanders (FWO).
The author would like to thank Burcu Korkmazer for managing the data collection phase, and Sofie Van Bauwel as supervisor of the research project.

\section{Conflict of Interests}

The author declares no conflict of interests.

\section{References}

Ang, I. (1995). Living room wars: Rethinking media audiences for a postmodern world. Routledge.

Bourdieu, P. (1994). Rethinking the state: Genesis and structure of the bureaucratic field. Sociological Theory, 12(1), 1-18.

Cremin, C. (2012). The social logic of late capitalism: Guilt fetishism and the culture of crisis industry. Cultural Sociology, 6(1), 45-60. https://doi.org/ $10.1177 / 1749975511427650$

De Ridder, S. (2019). Sexting as sexual stigma: The paradox of sexual self-representation in digital youth cultures. European Journal of Cultural Studies, 22(5/6), 563-578. https://doi.org/10.1177/ 1367549418810080

Gandini, A. (2016). The reputation economy: Understanding knowledge work in digital society. Palgrave Macmillan.

Gillespie, T. (2018). Custodians of the internet: Platforms, content moderation, and the hidden decisions that shape social media. Yale University Press.

Grazian, D. (2018). Demystifying authenticity in the sociology of culture. In L. Grindstaff, L. Ming-Cheng, \& J. R. Hall (Eds.), Routledge handbook of cultural sociology (pp. 191-200). Routledge.

Hall, S. (1997). Race the floating signifier [Lecture transcript]. Media Education Foundation. https:// www.mediaed.org/transcripts/Stuart-Hall-Race-theFloating-Signifier-Transcript.pdf

Hesmondhalgh, D. (2017). Capitalism and the media: Moral economy, well-being and capabilities. Media, Culture \& Society, 39(2), 202-218. https://doi.org/ $10.1177 / 0163443716643153$

Kirkpatrick, D. (2010). The Facebook effect: The inside story of the company that is connecting the world. Simon Shuster.

Korkmazer, B., De Ridder, S., \& Van Bauwel, S. (2020). Reporting on young people, sexuality, and social media: A discourse theoretical analysis. Journal of Youth Studies, 23(3), 323-339. https://doi.org/ 10.1080/13676261.2019.1603365

Kurzman, C., Anderson, C., Key, C., Lee, Y. O., Moloney, M., Silver, A., \& Van Ryn, M. W. (2007). Celebrity status. Sociological Theory, 25(4), 347-367. https:// doi.org/10.1111/j.1467-9558.2007.00313.x

Leaver, T., Highfield, T., \& Abidin, C. (2020). Instagram. Polity.

Lovink, G. (2012). Networks without a cause: A critique of social media. Polity. 
Madden, M., Cortesi, S., Gasser, U., Lenhart, M., \& Duggan, M. (2013). Teens, social media, and privacy. Pew Research Center. https://www.pewresearch. org/internet/2013/05/21/teens-social-media-andprivacy

Manovich, L. (2020). The aesthetic society: Or how I edit my Instagram. In P. Mörtenboeck \& H. Mooshammer (Eds.), Data publics (pp. 192-212). Routledge.

McGuigan, J. (2014). The neoliberal self. Culture Unbound, 6(1), 224-240.

Moran, M. (2014). Identity and capitalism. SAGE.

$\mathrm{Ng}$, E. (2020). No grand pronouncements here...: Reflections on cancel culture and digital media participation. Television \& New Media, 21(6), 621-627. https://doi.org/10.1177/1527476420918828

Origgi, G. (2019). Reputation: What it is and why it matters. Princeton University Press.

Phillips, W., \& Milner, R. M. (2017). The ambivalent internet: Mischief, oddity, and antagonism online. Polity.

Pink, S. (2013). Doing visual ethnography. SAGE.

Pink, S., Horst, H., Postill, J., Hjorth, L., Lewis, T., \& Tacchi, J. (2015). Digital ethnography: Principles and practice. SAGE.

Ronson, J. (2015). So you've been publicly shamed. Riverhead Books.

Rosamond, E. (2019). From reputation capital to reputation warfare: Online ratings, trolling, and the logic of volatility. Theory, Culture \& Society, 37(2), 105-129. https://doi.org/10.1177/0263276419872530
Salter, M. (2016). Privates in the online public: Sex(ting) and reputation on social media. New Media \& Society, 18(11), 2723-2739. https://doi.org/10.1177/ 1461444815604133

Sayer, A. (2007). Moral economy as critique. New Political Economy, 12(2), 261-270. https://doi.org/ $10.1080 / 13563460701303008$

Schultz, M., Hatch, M. J., \& Larsen, M. H. (Eds.). (2000). The expressive organization: Linking identity, reputation, and the corporate brand. Oxford University Press.

Shinkle, E. (2004). Boredom, repetition, inertia: Contemporary photography and the aesthetics of the banal. Mosaic: An Interdisciplinary Critical Journal, 37(4), 165-184. http://www.jstor.org/stable/44030032

Srnicek, N. (2016). Platform capitalism. Polity.

Sue, H., Rachel, B., Elizabeth, C., \& Eleanor, I. (2009). Researching young people's lives. SAGE.

Thompson, J. B. (2011). Shifting boundaries of public and private life. Theory, Culture \& Society, 28(4), 49-70. https://doi.org/10.1177/0263276411408446

van Dijck, J. (2013). "You have one identity": Performing the self on Facebook and LinkedIn. Media, Culture \& Society, 35(2), 199-215.

van Zoonen, L. (2013). From identity to identification: Fixating the fragmented self. Media, Culture \& Society, 35(1), 44-51. https://doi.org/10.1177/ 0163443712464557

\section{About the Author}

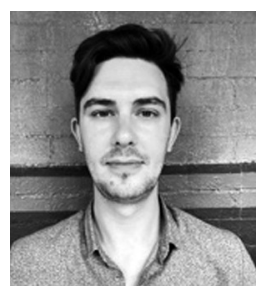

Sander De Ridder (PhD, Ghent University) is Assistant Professor of media studies at the University of Antwerp, Belgium. His research focuses on digital media, everyday life, the self, and identity. He has published widely on digital youth cultures, intimacy, and sexuality. 